\title{
BOLETIM DA SECRETARIA DE EDUCAÇÃO E CULTURA DO PARANÁ (1951 - 1953): REPRESENTAÇÕES SOBRE A ESCOLA RURAL
}

\begin{abstract}
Simone Burioli Ivashita ${ }^{1}$
Analete Regina Schelbauer ${ }^{2}$

\section{Resumo}

O presente artigo tem por objetivo reconstituir nuances do debate em torno da escola primária rural, a partir das representações de professores e professoras publicadas no Boletim da Secretaria de Educação e Cultura do Estado do Paraná, editado entre os anos de 1951 e 1953. A análise incide sobre a atuação da imprensa pedagógica oficial na produção e circulação de ideias acerca do que, politicamente, pretendia-se imprimir à formação e atuação docente acerca da escola e do ensino rural. Teoricamente, apoia-se no conceito de representação, desenvolvido pelo francês Roger Chartier (1990, 2002a, 2002b, 2009), para descortinar o que o Boletim apresenta sobre a referida categoria. A hipótese é que tal periódico representou um dos meios utilizados pelo Estado para a formação e aperfeiçoamento dos professores, tendo em vista o alto percentual de professores leigos que atuavam nas escolas isoladas das áreas rurais na década de 1950. Dentre as diversas temáticas apresentadas pelo periódico, a opção pela escola rural se deve ao fato de levar em consideração sua significativa expansão naquele momento e por entender que este era o modelo de escola primária que podia atender a um maior número de crianças no Estado do Paraná.
\end{abstract}

Palavras-chave: Educação. História da educação. Imprensa pedagógica. Escola rural.

\section{PARANÁ STATE EDUCATION AND CULTURE OFFICE'S BOLETIM (1951 - 1953): REPRESENTATIONS ON RURAL SCHOOL}

\begin{abstract}
This article aims to reconstitute nuances of rural primary school debate; supported by the teachers representations published in Paraná State Education and Culture office's Boletim, between the years of 1951 and 1953. The focus of this analysis relies on the official pedagogical press performance when producing and circulating ideas about what was politically intended to stamp the training and teaching performance concerning school and rural education. Theoretically, it is based on the concept of representation, developed by the French historian Roger Chartier (1990; 2002a; 2002b; 2009), to expose the Boletim's view upon the quoted category. The hypothesis presented is that this periodical represented one of the tactics used by the State to form and improve teachers at the time approached, given the high percentage of lay teachers who used to work in isolated schools at rural areas in the 1950s. Among the diverse themes presented at the periodical, the option for
\end{abstract}


rural school is due to the fact of taking into account its significant expansion in that time and the understanding that this model was the one wich attended the greatest number of children in the State of Paraná.

Keywords: Education. History of education. Pedagogical press. Rural school.

\section{INTRODUÇÃO}

O ideal seria organizar centros sociais rurais, com educadores especializados a fim de empreenderem no local em que são esses centros estabelecidos, trabalho eficiente de preparo do público campesino. (PARANÁ, 1952a, p. 233-235).

A epígrafe inicial refere-se ao artigo escrito pela professora Amália Barreiros, do corpo docente do Grupo Escolar de Cambará, intitulado "Escola rural - características próprias", no qual discute a importância dos centros sociais rurais como forma de educar o campesino no campo e para o campo, questão tangente no cenário nacional do período em foco.

A escrita remete à fonte da publicação: o Boletim da Secretaria de Educação e Cultura do Estado do Paraná, periódico da imprensa pedagógica oficial, editado entre os anos de 1951 e 1953 e definido enquanto fonte e objeto do presente artigo, por seu papel preponderante de orientação ao magistério, tendo sido considerado como um guia prático do cotidiano educacional, a partir da concepção de que a imprensa é portadora e produtora de significações, da difusão de ideias, modelos, pontos de vista e prescrições.

A finalidade foi compreender como a imprensa atuou na produção e circulação de ideias acerca do que, oficialmente, pretendia-se em relação ao ensino primário, a formação e atuação de professores e a expansão da escola rural no estado. A pesquisa empreendida teve como objetivo problematizar a formação de professores no Paraná e suas representações em meio aos desafios enfrentados quanto à expansão da escola primária para as zonas rurais.

Metodologicamente, o caminho adotado foi a realização da coleta e classificação dos conteúdos do Boletim, no sentido de identificar categorias que pudessem auxiliar neste percurso investigativo. Dentre as diversas temáticas apresentadas pelo periódico, a opção pela escola rural se deve ao fato de levar em consideração sua significativa expansão naquele momento e por entender que este era o modelo de escola primária que podia atender a um maior número de crianças. A escola rural pode ser entendida como a materialização da extensão da escola primária no Estado do Paraná.

Teoricamente, apoia-se no conceito de representação, desenvolvido pelo francês Roger Chartier (1990, 2002a, 2002b, 2009), para descortinar o que o Boletim apresenta sobre a referida categoria em relação à escola rural, importante lócus de atuação do (a) professor (a) paranaense no período em foco. 
A hipótese da qual partimos é que tal periódico representou um dos meios utilizados pelo Estado para a formação e aperfeiçoamento dos professores em exercício do magistério, tendo em vista, na década de 1950, a presença ainda significativa de professores leigos no Paraná. Além disso, o Boletim se destinava à organização da escola primária paranaense e, por ser uma fonte oficial, dava indícios do que era prescrito para essa formação e/ou atuação. Neste sentido, o periódico representou um dos meios utilizados pelo Estado para a formação e aperfeiçoamento dos professores que atuavam nas escolas isoladas das áreas rurais na década de 1950.

\section{HISTÓRIA DA EDUCAÇÃO E IMPRENSA: O BOLETIM}

Nas últimas décadas, a produção crescente da historiografia da educação brasileira acerca da temática: educação e imprensa e a ampliação do cabedal de fontes abrangendo a imprensa de educação e ensino, evidenciaram a importância da imprensa pedagógica para a compreensão do campo educativo. Assim como, a potencialidade de suas fontes e objetos temáticos para compreensão de um lugar, um momento histórico e uma prática pedagógica.

Neste sentido, Vidal e Camargo (1992, p. 408) argumentam que o interesse em "[...] estudar periódicos para a realização de análises históricas reside na possibilidade da leitura de manifestações contemporâneas aos acontecimentos". O historiador trabalha sobre um material para transformá-lo em história, ou seja, empreende uma manipulação, portanto o 'fazer historiográfico' implica em uma prática.

Nóvoa (2002) em seus escritos sobre a temática pondera ser difícil encontrar outro corpus documental que traduza com tanta riqueza de detalhes os debates, os atores e as questões essenciais a educação, quanto à imprensa.

Por refletir ideias em debate, proposições e valores, a imprensa pedagógica possibilita um vasto campo de análise ao pesquisador, como dimensiona Bastos (2002, p. 49):

\footnotetext{
A imprensa pedagógica - jornais, boletins, revistas, magazines, feita por professores para professores, feita para alunos por seus pares ou professores, feita pelo Estado e outras instituições como sindicatos, partidos políticos, associações de classe, igreja - contém e oferece muitas perspectivas para a compreensão da história da educação e do ensino. Sua análise possibilita avaliar a política das organizações, as preocupações sociais, os antagonismos e filiações ideológicas, as práticas educativas.
}

Ao registrar a importância do estudo e reafirmar o papel da imprensa periódica pedagógica na orientação intelectual e moral do magistério, a autora nos permite pressupor que, para muitos professores, a imprensa é adotada como um guia prático do cotidiano educacional e escolar. 
Antonio Nóvoa (2002, p. 12-13) reitera esta ideia ao destacar a imprensa como o melhor meio para apreender a multiplicidade do campo educativo, à medida que:

[...] revela múltiplas facetas dos processos educativos, numa perspectiva interna ao sistema de ensino (cursos, programas, currículos, etc), mas também no que diz respeito ao papel desempenhado pelas famílias e pelas diversas instâncias de socialização das crianças e jovens. A imprensa constitui uma das melhores ilustrações de extraordinária diversidade que atravessa o campo educativo.

O universo da fala no tempo contempla muitos fatos discursivos que possibilitam dimensionar melhor os debates, possibilitando-nos olhar para cada época de forma única e não como parte de um processo histórico que se desenrola simplesmente por meio de causas e consequências, em uma linearidade simplista. "O significado de cada época, buscado nas referências do momento $\mathrm{e}$, não, na interpretação a posteriori, pode redimensionar nossa percepção do período, permitindo-nos vislumbrar lutas e inquietudes numa paisagem que considerávamos harmônica”. (CAMARGO; VIDAL, 1992, p. 409).

Antecipadamente, é preciso marcar que utilizar como fonte a imprensa pedagógica no Brasil é uma tarefa um tanto complexa, visto que as pesquisas existentes ainda advertem para a necessidade de adensar a temática dentro da História da Educação, de modo a "[...] aprofundar os aspectos ligados aos usos, aos manuseios, às formas de apropriação e de leitura dos materiais impressos". (BICCAS, 2002, p. 176).

Luca (2008) indica que há muitos acervos de periódicos por todo o país, localizados nas Universidades, museus, institutos e Arquivos Públicos, que contêm coleções significativas de periódicos. A autora alerta, porém, que uma questão que se sobressai nas pesquisas com este tipo de fonte é a condição em que se encontra o material, porque "[...] nem sempre os exemplares estão organizados ou microfilmados à espera do pesquisador. Pode-se enfrentar situações longe da ideal, com exemplares em péssimo estado de conservação". (p. 141-142). Outra questão que se coloca importante para viabilizar as pesquisas com periódicos é a localização de séries completas, que, muitas vezes, demanda uma peregrinação por várias instituições.

Temos por conhecimento que a imprensa, de modo geral, preconiza uma suposta imparcialidade, aliás, esta é uma das suas maiores bandeiras, porém:

[...] a imparcialidade não passava, e não passa ainda hoje, de mera retórica, sendo usada para preservar o discurso e os interesses do próprio veículo. A neutralidade jornalística é um mito cotidianamente desfeito nas relações, a partir da elaboração da pauta que determina a forma de se buscar os fatos, o conteúdo pretendido e, eventualmente, indica os propósitos da editora. (LUSTOSA, 1996, p. 22).

A imprensa veicula informações que traz concepções e ideias dos mais diversos campos, entretanto tais informações e concepções não estão isentas de uma ideologia. Araújo (2002, p. 95) defende que é preciso recusar a ideia de que "[...] a imprensa seja apenas veiculadora de informações, imbuída de imparcialidade e de neutralidade diante dos 
acontecimentos, como se essa imprensa pudesse constituir uma ilha diante da realidade histórica na qual se insere".

Neste trabalho, especificamente, nosso interesse incide na imprensa pedagógica oficial, a qual pode ser diferenciada da imprensa em geral pelo seu lugar de produção e pelo público alvo, qual sejam alunos, professores, diretores de escolas entre outros. Compreendemos que a imprensa ocupa um lugar estratégico diante dos fenômenos educacionais e sociais e isso fortalece as opções do pesquisador que toma por fonte o impresso como o intuito de retomar o

[...] discurso pedagógico, das práticas educativas, do cotidiano escolar, do grau de submissão dos professores a programas e instruções oficiais, da ideologia oficial e do corpo docente, da força de inovação e de continuidade que representa, das contradições do discurso. (BASTOS, 2002, p. 153).

A imprensa permite observar, identificar e compreender a trajetória das atividades humanas, no caso específico deste trabalho, a trajetória da organização educacional, levando em consideração as singularidades que permearam a educação neste estado no momento histórico delimitado para estudo. Assim, a imprensa é portadora e produtora de significações, difunde e defende ideias e pontos de vista, podendo, portanto, ser entendida como um meio de formação do cidadão. O discurso da imprensa é carregado de simbolismos e age como mediador cultural e ideológico. (BASTOS, 2002). Este discurso carregado de verdades legitima alguns conhecimentos em detrimento de outros, valida determinadas práticas e saberes em detrimento de outros.

É importante destacar o que fora afirmado por Gonçalves Neto (2002, p. 205) que "Se o texto é fruto da concepção de uma determinada elite letrada, ele não corresponde integralmente à realidade, mas compõe uma interpretação, uma representação do real, formulada em um determinado momento, sob a influência de concepções específicas". A parir desse sentido, consideramos que as notícias necessitam de um filtro constante, para que não tomemos o noticiado como sendo toda a realidade. O exercício da dúvida, mais que nunca, deve se fazer presente quando analisamos representações do passado, tendo em vista que é por meio da imprensa que se propalam e solidificam as principais representações sociais.

A imprensa pedagógica fornece pistas sobre a circulação de ideia e modelos educativos, além de indicar as múltiplas dimensões de atuação do campo pedagógico, evidenciando a atuação dos grupos e personagens que atuaram no campo educacional em determinada época.

A categoria na qual o nosso exemplar de Imprensa Pedagógica, o Boletim da Secretaria de Educação e Cultura, enquadra-se é a de periódicos para professores, inspetores, delegados e demais funcionários, publicado pela Secretaria de Educação do Estado do Paraná. O conteúdo do Boletim abre possibilidades de olhar para aquele momento histórico, no que diz respeito às questões afetas ao campo educacional, particularmente para aventar quais os grupos de pessoas que indicavam o que deveria ou 
poderia ser veiculado naquele periódico, qual o tom que a profissão docente deveria tomar e o que se esperava da escola rural no Estado do Paraná.

Catani (1989; 1996) chama a atenção para as potencialidades da investigação acerca das revistas de ensino e reafirma a limitação ao acesso dos dados na pesquisa educacional. Neste sentido, a autora propõe a organização de repertórios analíticos e catálogos de referências básicas que sistematizem as informações e auxiliem os pesquisadores em suas empreitadas.

A pesquisa com a imprensa e a partir da imprensa periódica pode ser norteada por duas perspectivas:

\begin{abstract}
A primeira delas, constitui-se pela investigação que visa a estabelecer uma história serial e repertórios analíticos destinados a informar sobre o conteúdo dos periódicos, classificando-os, registrando seu ciclo de vida, predominâncias ou recorrências temáticas e informações sobre produtores, colaboradores e leitores, entre outros dados. Tais repertórios podem fornecer materiais básicos, dados que funcionam como ponto de partida para a localização de informações para pesquisas sobre história da educação, das práticas ou das disciplinas escolares e dos sistemas de ensino. [...] uma outra diretriz de trabalho se configura pelo estudo específico e "interno" ao próprio periódico e sua produção, a partir do qual é possível reconstruir, num momento dado, estágios de funcionamento e estruturação do campo educacional, movimentos de grupos de professores, disputas e atuações. Dito de outro modo, é possível partir do estudo de determinados periódicos educacionais e tomá-los como núcleos informativos, enquanto suas características explicitam modos de construir e divulgar o discurso legítimo sobre as questões de ensino e o conjunto de prescrições ou recomendações sobre formas ideais de realizar o trabalho docente. (CATANI, 1996, p. 118).
\end{abstract}

Há, ainda, a perspectiva da investigação sobre a produção de um determinado tema, identificando-o em vários periódicos, neste caso, o que se ganha em amplitude, perde-se em especificidade.

O objetivo do Boletim da Secretaria de Educação e Cultura indica que tal periódico pedagógico era necessário para que se estabelecesse "[...] uma ligação mais estreita entre os professores, inspetores, delegados e demais funcionários entre si e com a Secretaria de Educação e Cultura [...]" num esforço de fazerem-se conhecidas por estes "[...] as normas, resoluções, despachos, instruções, e atos atinentes ao ensino". (PARANÁ, 1951a, p. 114$115)$.

Tal periódico contou com a colaboração da comunidade, não tendo um colunista fixo, nem uma temática que direcionasse as matérias. Podemos encontrar assuntos dos mais variados: ensino e aprendizagem, folclore, religião, castigos físicos, tecnologia educacional, cultura paranaense, higiene, metodologias, poemas, professor e aluno, avaliação escolar, analfabetismo, diretrizes, dentre outros.

O Boletim da Secretaria de Educação e Cultura circulou entre os anos de 1951 e 1953, com periodicidade irregular, sendo localizadas e catalogadas dez edições dos 12 
números que foram publicados. Não foram encontradas informações acerca da interrupção da publicação e nem sobre uma possível continuidade para além do último exemplar que localizamos. Cabe destacar que o número de páginas foi bastante irregular em todos os números encontrados, bem como os intervalos de cada publicação por ano. Partilhamos do entendimento de Maurilane Biccas (2008, p. 83), que investigou um impresso para a formação de professores no Estado de Minas Gerais, segundo a autora:

\begin{abstract}
A análise desses aspectos é fundamental para compreendermos o ciclo de vida de um impresso. $\mathrm{O}$ fato de uma revista sair quinzenalmente, mensalmente, bimestralmente, trimestralmente, de ficar vários meses sem circular, além de condensar muitos números em um mesmo exemplar, pode, de um lado, ser indício de que o impresso está se consolidando, que está alcançando uma estabilidade. Por outro lado, tudo isso pode também indicar prioridades, disputas e problemas enfrentados pelo poder público na implementação de suas ações.
\end{abstract}

Diante das análises e ponderações da historiografia sobre o tema, considera-se que o Boletim apresenta com um potencial para apreensão das questões que permearam as tematizações em torno da formação e atuação de professores em um de seus principais lócus - a escola rural em franco processo de expansão.

Para a discussão do trabalho, incluímos a explanação do conceito de representação (CHARTIER, 1990, 1999, 2002a, 2002b, 2003, 2004, 2009) que nos valemos para realizar as análises das categorias encontradas no Boletim.

Destacamos que as matérias do Boletim são assumidas como representação, o intento é elucidar o que o Boletim reforça como sendo características do ensino/escola rural no estado do Paraná.

Nas palavras de Chartier (1990, p. 17), uma representação social seria “[...] a forma como uma realidade social é construída, pensada, dada a ler". Reafirmamos, por isto, que as representações são procedentes ou decorrências de práticas sociais. Por se considerar este princípio, a representação não pode ser desarticulada de seu contexto, daí a proposta do autor em tomar tal conceito em um sentido "[...] mais particular e historicamente mais determinado". O autor conceitua representação como "[...] a exibição de uma presença, como a apresentação pública de algo ou de alguém”. (CHARTIER, 1990, p. 20).

Para ele, representar é, pois, essencialmente, colocar-se no lugar de, é a personificação de um ausente; como o próprio nome indica é um apresentar de novo, que dá a ver uma ausência. Ainda sobre esta questão, afirma que "[...] a representação é um instrumento de um conhecimento mediato que faz ver o objeto ausente através da sua substituição por uma 'imagem' capaz de o reconstruir em memória e de o figurar como ele é”. (CHARTIER, 1990, p. 20).

Sendo assim, percebemos como um elemento que autoriza "[...] ver uma coisa ausente[...]", tornando possível a "[...] exibição de uma presença". (CHARTIER, 1990, p. 23). A representação pode ser entendida como a possibilidade de ilustrar, delinear, desenhar e, por vezes, substituir um símbolo ou uma ideia. Neste sentido, as pessoas 
representam, culturalmente, de diversas maneiras o seu entendimento de mundo, nas palavras do autor, "[...] a realidade é contraditoriamente construída pelos diferentes grupos". Portanto, as representações culturais são intrinsecamente ligadas aos interesses dos grupos sociais.

Ao tomarmos como base analítica as representações culturais, é plausível afirmar que permanecem tensões entre os grupos, assim as relações são permeadas de conflitos/crises que permitem uma elasticidade nas concepções de mundo social e nas lutas de representações, as quais também foram abordadas por Chartier (1990, 2002a). É preciso enfatizar que a representação nem sempre se estabelece de maneira pacífica, tendo em vista que possíveis conflitos podem acontecer, demonstrando uma disputa de espaço, e, por conseguinte, de poder.

A representação pode legitimar, autenticar e até autorizar um modo de ser e estar em sociedade, possibilitando afirmar que "[...] as lutas de representações têm tanta importância como as lutas econômicas para compreender os mecanismos pelos quais um grupo impõe, ou tenta impor, a sua concepção do mundo social, os valores que são os seus, e o seu domínio". (CHARTIER, 1990, p. 17).

Em seus estudos, Chartier evidencia que as representações possibilitam compreender como um grupo impõe os seus valores e o seu domínio. Os atores idealizam uma sociedade de acordo com os seus propósitos, objetivando atender aos seus interesses. Nas suas palavras, representação "[...] é o instrumento de um conhecimento mediato que revela um objeto ausente, substituindo-o por uma 'imagem' capaz de trazê-lo à memória e pintá-lo como é [...]”. (CHARTIER, 2002a, p. 74).

Por considerar que os Boletins informam e disciplinam ao mesmo tempo, nosso enfoque está voltado para as representações divulgadas sobre as representações docentes, manifestas neste impresso, acerca da escola/ensino rural.

\section{PARANÁ: UM ESTUDO QUE SE MODERNIZA}

O recorte temporal deste artigo incide sobre um período em que o estado do Paraná encontrava-se em franco processo de modernização e desenvolvimento econômico, propiciados, sobretudo, pela expansão agrícola. Momento no qual a educação escolar despontava no cenário estadual como um dos fatores centrais desse processo de modernização a partir da expansão da rede pública de ensino urbana e rural a partir da década de trinta, do século XX.

Acerca do período que antecede a esse movimento de expansão do ensino primário e da rede de escolas no espaço urbano e rural, a historiografia da educação paranaense tem evidenciado que ao final do período provincial, o Estado do Paraná contava com um número significativo de escolas primárias, mas insuficientes para suprir a necessidade de instrução escolar da maioria da população. Miguel (2006, p. 195) indica que o governo 
provincial assumiu a responsabilidade de manter e organizar a instituição escolar primária entre os anos de 1853 e $1889^{3}$, mas apesar de muitos regulamentos, decretos e leis, expedidos, "[...] pouca diferença teve na prática, pois as carências e dificuldades não se deram apenas na formação da nova província, mas sim durante toda sua existência".

A criação das escolas primárias ocorreu com o intuito de atender à população que vivia à margem das colônias, eram denominadas de "casas-escolas ou escolas isoladas". Tais escolas, de acordo com Nascimento (2006) eram organizadas precariamente com pouca luz e salas sem ventilação e funcionavam sob a regência de um único professor, que ensinava alunos de diferentes séries em uma única sala. Em suas pesquisas sobre os grupos escolares na região dos Campos Gerais, Nascimento (2006, p. 327) afirma que, apesar do estado precário em que se encontravam as escolas, sempre havia, por parte das autoridades da época, reivindicações para a construção de escolas adequadas:

\begin{abstract}
A instalação da República no país sem uma organização escolar elementar aparelhada e sem professores preparados para atender à população, tornou-se pano de fundo para inculcar os ideais liberais republicanos da educação elementar, o que havia era uma preocupação marcante em acabar com o analfabetismo por meio da escola elementar para o povo.
\end{abstract}

A ideia de oferecer escola elementar para o povo, como instrumento para forjar o cidadão, colocada em circulação em âmbito nacional e internacional nas últimas décadas do século XIX e no início do século XX, foi apropriada e colocada em circulação no meio educacional: "[...] no início do século XX, a educação foi percebida como solução para formar o novo cidadão trabalhador, disciplinado e higiênico, capaz de mudar o perfil do povo deixado pelo sistema escravocrata". (MIGUEL; VIEIRA, 2005, p. 3). A República, no Paraná, assim como nos demais estados da Federação, tinha por objetivo difundir a escola primária e o Estado seria o responsável pela propagação do ensino ao povo, bem como por arcar com os custos dessa educação: "Já nos primeiros anos da República as autoridades paranaenses enfatizavam a instrução do povo como sendo o padrão por onde se poderia medir o estágio de civilização de uma nação. A instrução representava a base estável da prosperidade pública". (SCHENA, 2002, p. 31).

As novidades pedagógicas que vieram com os grupos escolares, durante a Primeira República, foram os quadros negros, as carteiras e as cadeiras individuais. Entendia-se que o projeto civilizatório e de modernização da sociedade aconteceria via educação, portanto construir escolas era um dos objetivos desse período. De acordo com Castro (2009, p. 142), durante a primeira república foram construídos 36 edifícios destinados à instrução primária no estado:

[...] grande número dessas escolas na capital do Estado. Curitiba ganhou, no período, oito edifícios projetados e construídos como escolas primárias, enquanto as demais cidades, quando contempladas, receberam apenas um. [...] São curitibanos o primeiro e o último grupo escolar da Primeira República, o Dr. Xavier da Silva e do D. Pedro II. Eles podem ser considerados marcos referenciais da arquitetura escolar e do processo de constituição e disseminação de escolas públicas no Paraná. O primeiro iniciou o processo, dentro da concepção de graduação do ensino; o segundo materializou a sua consolidação, já amadurecida pelo percurso de 25 anos. 
Dentre os feitos das monumentais construções republicanas, o Paraná também criou o seu Grupo Escolar ${ }^{4}$ na capital do Estado - Curitiba, denominado "Grupo Escolar Dr. Gabriel Xavier da Silva", no ano de 1903, a partir do modelo e estrutura dos grupos escolares do Estado de São Paulo. (OLIVEIRA, 2000).

Acerca da temática (NASCIMENTO, 2006, p. 333), retrata que:

A criação dos grupos escolares representava uma medida econômica, pois reunia duas ou mais escolas que funcionavam na mesma localidade, com vários alunos de séries diferentes e uma equipe de trabalho, todo num mesmo prédio, que reunia as necessidades de condições de capacidade e de higiene, construindo uma organização administrativa e didático-pedagógica.

No Paraná, embora o processo de escolarização do povo tenha acompanhado arquétipos nacionais, recebeu a influência de diferenciais trazidos pela imigração, pela economia fundamentada na erva-mate e no café, pelo comércio com a Argentina, Paraguai e Uruguai. (MIGUEL, 1992).

É inegável que a criação dos grupos escolares colaborou para a formação do cidadão e para o processo de modernização do estado. Nesse momento, a instrução buscava alcançar o maior contingente possível da população. Trindade e Andreazza (2001, p. 80) explicam que, em 1917, o Paraná registrava uma população escolar de 15.101 alunos de ambos os sexos. Em 1922, esse total havia alcançado 34.676 alunos.

A disseminação das escolas primárias refletia, à época, o chamado "entusiasmo pela educação" do período republicano que corporificava a crença de que a multiplicação das instituições escolares conduziria a uma popularização do ensino, determinante do desenvolvimento das nações posição muitas vezes expressas nas palavras das autoridades educacionais.

Ao retratar o cenário da educação no Paraná nas primeiras décadas republicanas, é imperioso mencionar os nomes de personagens que figuraram na realização de reformas de ensino e estiveram na direção do ensino paranaense como César Prieto Martinez, Lysímaco Ferreira da Costa e Erasmo Pilotto. Em seus escritos, Miguel (1992) tem destacado o papel desses educadores nas reformas da instrução primária e da escola normal, à frente da Escola de Professores do Paraná e, principalmente, vinculados ao movimento de expansão da escola primária e do ensino normal.

Tratar das primeiras iniciativas republicanas acerca da instrução pública, dos principais personagens de suas reformas, requer também retratar as questões tangentes da época: o ensino/a escola primária e a formação de seus professores. Como um dos fóruns de discussão destas questões, o Paraná sediou dois grandes eventos na área: o "Congresso de Ensino Primário em 1926" e a "Primeira Conferência Nacional de Educação em 1927", reunindo intelectuais, professores e políticos com o objetivo de discutir a educação. (BONA JÚNIOR; VIEIRA, 2007). Em ambos, a educação rural desponta como um dos temas das conferências e revela as faces do debate que se instaurou na sociedade brasileira em torno da escola primária no meio rural. 
Nas décadas seguintes, a educação no meio rural continuou sendo foco de discussão, como aponta Werle (2007, p. 161):

\begin{abstract}
A educação rural foi discutida sob diferentes enfoques e sua valorização inspirou debates em várias das conferências nacionais de educação. A importância da educação rural, a vinculação da escola e seu meio, a formação pedagógica docente associada a conhecimentos de educação sanitária, higiênica e agrícola, eram debates que vinham, portanto, se configurando desde o $1^{\circ}$ Congresso de 1927.
\end{abstract}

Dentre as questões que entram em cena nas conferências da Associação Brasileira de Educação (ABE), nas publicações da época e na legislação, está o debate em torno da escola única versus escola diferenciada para o meio urbano e para o meio rural.

É importante considerar que neste momento, no Estado do Paraná e em outros estados da federação, os debates tangenciavam em torno do movimento que ficou conhecido como "ruralismo pedagógico", que tem em Sud Mennucci ${ }^{5}$ uma das figuras mais expressivas na defesa de uma escola rural integrada às condições locais, que promovesse a fixação do homem no campo.

A educação do meio rural, suas escolas, seu ensino e a formação e atuação de seus professores, também teve como fórum privilegiado o $8^{\circ}$. Congresso Brasileiro de Educação, promovido pela ABE, em 1942:

Era amplo o significado dado a esta educação; a orientação ruralista e o destaque à preservação da natureza deveriam compor as propostas de formação em âmbito nacional. A proposta é que em cidades do interior a educação deveria encaminhar para o conhecimento da vida rural do município, a exigência de bons produtos e noções sobre seu beneficiamento, cultivo em quintas e roças, o aprendizado de indústrias domésticas e o desenvolvimento do artesanato. (WERLE, 2007, p. 157).

O teor das discussões retratado por Werle (2007, p. 158), aponta para uma escola diferenciada para o meio rural, no entanto destaca que esta questão não foi consensual durante o Congresso. A tese apresentada por Rômulo de Almeida em torno do ruralismo e professorado propunha "[...] que não houvesse diferenciação nítida entre escola urbana e rural", expressando claramente as discussões entre escola única versus escola diferenciada ${ }^{6} "$

E como esse debate entre a escola comum e a ruralização do ensino, em circulação no cenário nacional, foi apropriado no Paraná? Quais representações foram manifestas por professores e professoras acerca da escola para o meio rural? Salientando-se que a zona rural do estado era representada como "[...] um espaço a ser desbravado, colonizado, modernizado pela construção das vias de acesso, comunicação e infraestrutura, sobretudo vinculada à produção agrícola que teve como cultura central no período: o café". (FURTADO; SÁ; SCHELBAUER, 2015, p. 110).

Outra preocupação que se colocava como imprescindível para a modernização do Estado era a saúde pública, a solução se deu por meio de campanhas empreendidas pela 
Secretaria da Saúde, com a finalidade de combater doenças como a malária, a doença de chagas, a lepra e a tuberculose.

Quanto ao percentual da população que vivia no meio rural entre as décadas de 1950 e 1960, este representava mais de 70\%, situação que começou a se alterar nos anos seguintes com o auge do processo de urbanização, industrialização e êxodo rural (FURTADO; SÁ; SCHELBAUER, 2015). De modo geral, pode-se constatar que o Paraná era um Estado eminentemente rural até meados da década de 1970.

No período delimitado para este estudo, a ação governamental desencadeou um amplo movimento em prol da criação e expansão das escolas primárias rurais e da formação de seus professores, esta impulsionada pela Lei Orgânica do Ensino Normal de 1946, com a criação dos Cursos Normais Regionais em todo o estado. No entanto, apesar desse movimento ter sido intenso, durante anos a escola rural contou com a figura do professor leigo, já que "[...] a formação específica não era garantia de que o professor exercesse sua docência nas áreas rurais, para as quais o deslocamento e as condições de trabalho nem sempre eram favoráveis". (FURTADO; SÁ; SCHELBAUER, 2015, p. 136). Corroborando com a análise, Miguel (2007), pondera que o grande problema da educação rural residia no fato de que os professores, quando formados em escolas urbanas, não permaneciam em escolas rurais para além do tempo exigido para o estágio obrigatório, que era de dois anos.

Neste aspecto, reitera-se a hipótese inicial de que o Boletim representou um dos meios utilizados pelo Estado para a formação e aperfeiçoamento dos professores em exercício no magistério primário rural, tendo em vista a significativa presença de professores leigos. Os artigos, as temáticas, as discussões ao difundir ideias, significações, modelos e prescrições, destinavam-se a organizar a escola primária rural que se expandia para o sertão.

Como foi salientado anteriormente, dentre as diversas temáticas apresentadas pelo periódico, a opção pela escola rural se deve ao fato de levar em consideração sua significativa expansão naquele momento e por entender que este era o modelo de escola primária que podia atender a um maior número de crianças no Estado do Paraná.

\section{REPRESENTAÇÕES DE ESCOLA RURAL NAS PÁGINAS DO BOLETIM}

Impressos nas páginas do Boletim, os artigos escritos por professores e professoras, abordaram temáticas, colocaram ideias em debate, produziram significações, modelos e prescrições destinadas a organizar a escola primária rural que se expandia para o sertão.

O olhar para a categoria da escola rural nas páginas do periódico, tem o intuito de refletir sobre as instituições educativas no Paraná, especificamente aquelas localizadas no 
campo, as quais, naquele momento, tinham por função educar o homem do campo com a finalidade de mantê-lo no campo.

A professora Amália Barreiros, do corpo docente do Grupo Escolar de Cambará, escreveu um artigo intitulado "Escola rural - características próprias", nele, discute a educação ligada às condições do meio, no sentido de que o indivíduo deve ser educado de acordo com o meio onde vive e defende a criação de centros sociais rurais.

\begin{abstract}
Infelizmente no Brasil, as escolas primárias, não estão ainda preenchendo de modo cabal, a sua finalidade. O Estado e a sociedade estão a carecer de que a escola encaminhe a sua ação mais relacionada, mais coerente com as necessidades da vida tudo processando de acordo e em harmonia com os interesses morais e materiais do meio onde opera. Mister se faz, fazer com que a escola seja um conjunto, um laboratório, onde desenvolvam, se acentuem, e se aperfeiçoem as atividades regionais que asseguram a manutenção do povo e das instituições. [...] Sob esse novo aspecto, na prática, eremos que organizar a escola, não só para a escola, mas para a vida. O ideal seria organizar centros sociais rurais, com educadores especializados a fim de empreenderem no local em que são esses centros estabelecidos, trabalho eficiente de preparo do público campesino. Deve-se instituir um tipo de escola em que, ao lado das generalidades do ensino das letras e das artes, ministremos conhecimentos que constituem principalmente o meio de vida dos habitantes da região. A criança da roça, ao deixar a escola primária, enfrenta desde logo às necessidades de auxílio à manutenção da família, indo trabalhar, e na maioria das vezes, já o fazem em época escolar. Para isso, se faz necessário que a escola primária procure orientar o aluno no sentido de possibilitar-lhe condições mais fáceis de ajustamento, levando-o a conhecer o campo profissional ou educacional em que penetrará. (PARANÁ, 1952a, p. 233-235).
\end{abstract}

A questão abordada pela professora Amália, encontrava-se em consonância com o prescrito no Programa para as Escolas Normais Regionais, desenvolvido pelo secretário da Educação Erasmo Pilotto em 1952, no qual enfatiza que uma das finalidades do curso era formar o professor-regente para que, ao conhecer as dificuldades da população local, pudesse fazer da escola "[...] um centro de vida social e educativo de tôda a comunidade". (HERVATINI; SCHELBAUER, 2012, p. 48; SCHELBAUER, 2014, p. 87). Deste modo, o professor atuaria em conjunto com os pais, orientando-os no cumprimento de suas responsabilidades com os filhos. Assim, o programa de ensino das escolas normais regionais deveria estar vinculado à formação da personalidade do professor para, ao alargar sua cultura, destinar a sua ação a objetivos assistenciais junto à comunidade, fosse ela rural ou urbana. (PILOTTO, 1952).

Ainda no mesmo número do Boletim, o artigo sobre o "Primeiro curso de aperfeiçoamento para professores primários rurais da região sudoeste do Paraná", realizado por iniciativa do Secretário de Educação e Cultura, João Xavier Viana, assegura que já era tempo de voltar às atenções, mais detidamente, para as escolas isoladas da zona rural. Sendo necessária a sua remodelação, visto que as condições em que tais instituições se encontravam, acabavam por distanciar ainda mais os alunos, levando-os a abandonando e desinteressarem-se pelos estudos. Metodologicamente, ele apresenta o que seria melhor ensinar para os meninos e meninas do campo: 
[...] para o aluno da roça, é muito mais importante saber a maneira de ordenhar uma vaca do que a lista completa dos reis da Inglaterra. É Sud Menucci ainda que escreve: A um menino do campo interessa muito mais fortemente aprender como se faz um enxerto do que decorar o inexpressivo rol das Capitanias Hereditárias e seus donatários; ou que, para uma menina campônia, é de muito maior utilidade aprender a organizar os menús diários e racionais para a dieta da família do que perder-se no cipoal da descrição das batalhas da guerra contra Lopes. (PARANÁ, 1952a, p. 259).

Do professor da escola rural, esperava-se não apenas que orientasse sua prática pelos novos fundamentos, mas, sobretudo, tivesse em mente a valorização do campo:

\begin{abstract}
Não basta a Escola, o Professor é que a movimenta. E o professorado sem orientação é semeador do mal. Não basta um professor formado em sua cultura apropriada ao Magistério, capaz de organizar a sua escola e sua classe de trabalho. Fundamental é que ele tenha mentalidade agrícola, que conheça, sinta o campo e os seus problemas, que se fixe, com ideias claras, que ame a terra. (PARANÁ, 1952b, p. 470).
\end{abstract}

Sob a mesma ótica, manter o homem do campo no campo, o artigo escrito por Cecília Maria Westphalen, intitulado "Necessidade da formação de professores rurais", inicia discorrendo sobre o desiquilíbrio econômico-financeiro na esperança do aumento da produção. Em seguida, volta sua ênfase para o campo, por ser "[...] o núcleo onde se forma a quase totalidade da riqueza, - o campo, vem perdendo, cada vez mais o seu lugar, de fato, dentro do nosso organismo político-sócio-econômico; e o seu habitante foge atrás das facilidades dos grandes centros". (PARANÁ, 1952b, p. 469). A autora indica que a salvação nacional depende de uma dupla tarefa:

1) - Valorização do campo. Dar a ele um lugar definido através do profundo conhecimento da terra e do aproveitamento nacional das suas possibilidades. 2) Fixação do homem à terra. A sua necessária formação, vivência de hábitos rurais, não a sua reforma, mas a renovação de valores, completa adaptação e integração à realidade brasileira. (PARANÁ, 1952b, p. 469-470, grifo nosso).

Retomando as questões elencadas anteriormente, pode-se inferir a partir dos três artigos em destaque nas páginas do Boletim, que as representações dos professores se aproximavam do movimento em prol de uma escola diferenciada para o meio rural, com a missão de formar o homem do campo para a vida no campo, integrando-o ao espaço, mobilizando a população a permanecer no meio rural. Alinhadas, por sua vez, com o debate no qual Sud Mennucci ocupou um papel de destaque na defesa de uma escola diferenciada para o homem do campo, o homem da cidade e o homem do mar. (SCHELBAUER, 2014, p. 85).

A partir dessa análise, pode-se apontar que o Boletim representou um elo entre a comunidade escolar e a Secretaria de Educação e Cultura do Paraná, com a finalidade de disseminar formas eficientes de organizar a escola e direcionar o ensino.

Como resultado, considera-se que o estudo, ao apontar nuances do debate em torno da escola primária rural, a partir das representações de professores e professoras publicadas 
no Boletim, descortinou umas das formas com que o Estado, por meio da Secretaria de Educação e Cultura, alcançou os professores e demais envolvidos com a escola, direcionando e indicando o que e como deveria ser a escola rural no Paraná.

\section{REFERÊNCIAS}

ARAÚJO, José Carlos Souza. Um capítulo da veiculação da discussão educacional na imprensa do triângulo mineiro: a revista A Escola (1920-1921). In: ARAÚJO, José Carlos Souza; GATTI JUNIOR, Décio (Org.). Novos temas em história da educação brasileira: instituições escolares e educação na imprensa. Campinas, SP: Autores Associados; Uberlândia, MG: Editora EDUFU, 2002. p. 91-132.

BASTOS, Maria Helena Câmara. As revistas pedagógicas e a atualização do professor: a revista do ensino do Rio Grande do Sul (1951-1992). In: CATANI, Denice Bárbara; BASTOS, Maria Helena Câmara (Org.). Educação em revista: a imprensa periódica e a história da educação. São Paulo: Escrituras, 2002. p. 47-75.

BICCAS, Maurilane de Souza. Da revista à leitura: a formação dos professores e a conformação do campo pedagógico em Minas Gerais (1925-1940). In: ARAÚJO, José Carlos Souza; GATTI JUNIOR, Décio (Org.). Novos temas em história da educação brasileira: instituições escolares e educação na imprensa. Campinas, SP: Autores Associados; Uberlândia, MG: Editora EDUFU, 2002. p. 175-196.

BICCAS, Maurilane de Souza. O impresso como estratégia de formação: revista do ensino de Minas Gerais (1925-1940). Belo Horizonte: Argvmentvm, 2008.

BONA JUNIOR, Aurélio; VIEIRA, Carlos Eduardo. O discurso da modernidade nas conferências educacionais na década de 1920 no Paraná. In: VIEIRA, Carlos Eduardo (Org.). Intelectuais, educação e modernidade no Paraná (1986-1962). Curitiba: Editora UFPR, 2007. p. 13-40.

CASTRO, Elizabeth Amorim de. A arquitetura dos grupos escolares do Paraná na Primeira República. Revista Brasileira de Estudos Pedagógicos, Brasília, DF, v. 90, p. 122-148, jan./abr. 2009.

CATANI, Denice Barbara. A imprensa periódica educacional: as revistas de ensino e o estudo do campo educacional. Educação e Filosofia, v. 10, n. 20, p. 115-130, jul./dez. 1996.

CATANI, Denice Barbara. Educadores à meia-lua: um estudo sobre a revista de ensino da Associação Beneficente do Professorado Público de São Paulo - 1902-1919. 1989. Tese (Doutorado em Educação) - Faculdade de Educação da Universidade de São Paulo, São Paulo, 1989. 
CHARTIER, Roger. A aventura do livro: do leitor ao navegador. Tradução de Reginaldo de Moraes. São Paulo: Editora da UNESP, 1999.

CHARTIER, Roger. À beira da falésia: a história entre incertezas e inquietudes. Tradução de Patrícia Chittoni Ramos. Porto Alegre: Editora UFRGS, 2002a.

CHARTIER, Roger. A história cultural: entre práticas e representações. Tradução de Maria Manuela Galhardo. Lisboa: Difel, 1990.

CHARTIER, Roger. A história ou a leitura do tempo. Tradução Cristina Antunes. Belo Horizonte: Autêntica, 2009.

CHARTIER, Roger. Formas e sentidos. Cultura escrita: entre distinção e apropriação. Tradução Maria de Lourdes Meirelles Matencio. Campinas, SP: Mercado de Letras; Associação de Leitura do Brasil (ALB), 2003.

CHARTIER, Roger. Leituras e leitores na França do antigo regime. Tradução Álvaro Lorencini. São Paulo: Editora da UNESP, 2004.

CHARTIER, Roger. Os desafios da escrita. Tradução de Fúlvia M. L. Moretto. São Paulo: Editora UNESP, 2002b.

FURTADO, Alessandra Cristina; SCHELBAUER, Analete Regina; SÁ, Elizabeth Figueiredo de. Escola primária rural: caminhos percorridos pelos estados de Mato Grosso e Paraná (1930-1961). In: SOUZA, Rosa Fátima de; PINHEIRO, Antonio Carlos Ferreira; LOPES, Antônio de Pádua Carvalho (Org.). História da escola primária no Brasil: investigações em perspectiva comparada em âmbito nacional. Aracaju: Edise, 2015. p. 103-146.

GONÇALVES NETO, Wenceslau. Representações de mulher e de educação na imprensa de Uberabinha (1910-1926). In: FARIA FILHO, Luciano Mendes et al. (Org.). História da educação em Minas Gerais. Belo Horizonte: FCH/FUMEC, 2002. p. 136-149.

HERVATINI, Luciana; SCHELBAUER, Analete Regina. A escola normal regional no interior do Paraná: a realidade e a idealidade de suas práticas pedagógicas. Revista HISTEDBR On-line. v. 12, n. 45, p. 296-309 mar. 2012. Disponível em: <http://www.fae .unicamp.br/revista/index.php/histedbr/issue/view/224>. Acesso em: 10 jan. 2017.

IVASHITA, Simone Burioli. Boletim da Secretaria de Educação e Cultura do Paraná (1951 - 1953): representações de ensino, professor e escola rural. 2016. 162 f. Tese (Doutorado em Educação) - Universidade Estadual de Maringá, Maringá, 2016.

LUCA, Tânia Regina de. História dos, nos e por meio dos periódicos. In: PINSKY, Carla Bassanezi (Org.). Fontes históricas. São Paulo: Contexto, 2008. p. 111-153.

LUSTOSA, Elcias. O texto da notícia. Brasília, DF: Editora UnB, 1996. 
MAIA, Eni Marisa. Educação rural no Brasil: o que mudou em 60 anos? Em Aberto, Brasília, DF, ano 1, n. 9, p. 27-33, set. 1982.

MENNUCCI, Sud. A crise brasileira de educação. Versão para eBook. eBooksbrasil. Fonte digital. Digitalização da 2. ed. em papel de 1934. São Paulo: Piratininga, 1934.

MIGUEL, Maria Elisabeth Blanck. A formação do professor para as escolas rurais e as políticas de educação do homem do campo. In: WERLE, Flávia Obino Correa (Org.).

Educação rural: práticas civilizatórias e institucionalização da formação de professores.

São Leopoldo: Oikos; Brasília, DF: Liber Livro, 2010. p. 74-90.

MIGUEL, Maria Elisabeth Blanck. A história da escola pública no Paraná: entre as intenções legais e as necessidades reais. In: SCHELBAUER, Analete Regina; LOMBARDI, José Claudinei; MACHADO, Maria Cristina Gomes. (Org.). Educação em debate: perspectivas, abordagens e historiografia. Campinas, SP: Autores Associados, 2006. p. 188.

MIGUEL, Maria Elisabeth Blanck. As escolas rurais e a formação de professores: a experiência do Paraná 1946-1961. In: WERLE, Flávia Obino Corrêa (Org.). Educação rural em perspectiva internacional: instituições, práticas e formação de professores. Ijuí: Ed. Unijuí, 2007. p. 79- 98.

MIGUEL, Maria Elisabeth Blanck. Pedagogia da escola nova na formação do professor primário paranaense: início, consolidação e expansão do movimento. 1992. 292 f. Tese (Doutorado em Educação) - Pontifícia Universidade Católica, São Paulo, 1992.

MIGUEL, Maria Elisabeth Blanck; VIEIRA, Alboni Marisa Dudeque Pianovski. A escola nova no Paraná: avanços e contradições. Revista Diálogo Educacional, Curitiba, v. 5, n. 14, p. 93-100, jan./abr. 2005.

NASCIMENTO, Maria Isabel Moura. Grupos escolares na região dos Campos Gerais (PR). In: VIDAL, Diana Gonçalves (Org.). Grupos escolares: cultura escolar primária e escolarização da infância no Brasil (1893-1971). Campinas, SP: Mercado de Letras, 2006. p. 323-337.

NÓVOA, António. A imprensa de educação e de ensino: concepção e organização do repertório português. In: CATANI; Denice Bárbara; BASTOS, Maria Helena Câmara. (Org.). Educação em Revista: a imprensa periódica e a história da educação. São Paulo: Escrituras, 2002. p. 11-31.

OLIVEIRA, Maria Cecília Marins de. O grupo escolar dezenove de dezembro: história e organização. In: CONGRESSO BRASILEIRO DE HISTÓRIA DA EDUCAÇÃO, 1., 2000. Anais eletrônicos... UFRJ, 2000. p. 1-12. Disponível em: <http://www.sbhe.org.br /novo/congressos/cbhe1/anais/099_maria_cecilia_martins.pdf >. Acesso em: 23 abr. 2015.

PARANÁ. Secretaria de Educação e Cultura. Boletim da Secretaria de Educação e Cultura do Estado do Paraná. Curitiba, ano 1, v. 3, jul./out. 1951. 
PARANÁ. Secretaria de Educação e Cultura. Boletim da Secretaria de Educação e

Cultura do Estado do Paraná, Curitiba, ano 2, v. 7, maio/jun. 1952a.

PARANÁ. Secretaria de Educação e Cultura. Boletim da Secretaria de Educação e

Cultura do Estado do Paraná, Curitiba, ano 3, v. 9, set./dez. 1952b.

PILOTO, Erasmo. A educação é direito de todos. Curitiba: Max Roesner, 1952.

SCHELBAUER, Analete Regina. Da roça para a escola: institucionalização e expansão das escolas primárias rurais no Paraná (1930-1960). Revista História da Educação, Porto Alegre, v. 18, n. 43, p. 71-91, maio/ago. 2014.

SCHENA, Denilson Roberto. O lugar da escola primária como portadora de um projeto de nação: o caso do Paraná (1890-1922). 2002. Dissertação (Mestrado em Educação) - Universidade Federal do Paraná, Curitiba, 2002.

SOUZA, Rosa Fátima de; ÁVILA, Virgínia. As disputas em torno do ensino primário rural (São Paulo, 1931-1947). Revista História da Educação, Porto Alegre, v. 18, n. 43, p. 1332, maio/ago. 2014.

TRINDADE, Etelvina Maria de Castro; ANDREAZZA, Maria Luiza. Cultura e educação no Paraná. Curitiba: SEED, 2001.

VIDAL, Diana Gonçalves; CAMARGO, Marilena Jorge Guedes de. A imprensa periódica especializada e a pesquisa histórica: estudos sobre o Boletim de Educação Pública e a Revista Brasileira de Estudos Pedagógicos. Revista Brasileira de Estudos Pedagógicos, Brasília, DF, v. 73, n. 175, set./dez. 1992.

WACHOWICZ, Lilian Anna. A relação professor/estado no Paraná tradicional. São Paulo: Cortez; Autores Associados, 1984.

WERLE, Flávia Obino Corrêa. Escola Normal Rural no Rio Grande do Sul: contexto e funcionamento. In: DIAS, Reginaldo Benedito; GONÇALVES, José Henrique Rollo. (Org.). Educação rural em perspectiva internacional. Ijuí, RS: Unijuí, 2007. p. 155-196.

\footnotetext{
Notas

1 Doutora em Educação pela Universidade Estadual de Maringá - UEM. Professora Adjunta no Departamento de Educação da Universidade Estadual de Londrina - UEL. E-Mail: si.ivashita@ gmail.com

2 Doutora em Educação pela Universidade de São Paulo - USP. Professora Associada no Departamento de Teoria e Prática da Educação e Programa de Pós-Graduação em Educação da Universidade Estadual de Maringá - UEM. E-Mail: analeteregina@ gmail.com

${ }^{3} \mathrm{O}$ Paraná esteve subordinado às determinações legais da província de São Paulo durante o período em que foi considerado como sua quinta Comarca, inclusive a respeito das questões ligadas ao ensino. A emancipação aconteceu em 29 de agosto de 1853 e Curitiba foi escolhida para ser sua capital.

${ }^{4}$ O programa para os Grupos Escolares foi aprovado pelo governador do Estado, Caetano Munhoz da Rocha, por meio da Portaria n $^{\circ} 86$, de 19 de agosto de 1921.

${ }^{5}$ Ver Sud Mennucci 1934.
} 
${ }^{6}$ Sobre a questão, consultar Souza e Ávila (2014).

Submetido em: 07/052017

Aprovado em: 30/06/2017 